Check for updates

Cite this: RSC Adv., 2017, 7, 45241

Received 19th July 2017

Accepted 16th September 2017

DOI: 10.1039/c7ra07979f

rsc.li/rsc-advances

\section{Green approach towards corrosion inhibition of carbon steel in produced oilfield water using lemongrass extract}

\begin{abstract}
M. A. Deyab, (D) *a M. M. Osman, ${ }^{a}$ A. E. Elkholy ${ }^{a}$ and F. El-Taib Heakal ${ }^{b}$
The anti-corrosion action of lemongrass (cymbopogon citratus) extract (LGE) was evaluated for carbon steel in produced oilfield water using weight loss method and electrochemical impedance spectroscopy (EIS). The results revealed that LGE serves as an effective corrosion inhibitor for C-steel via adsorption of its active constituents on the steel surface. The effect of time was studied by weight loss to assess the durability of the adsorbed film in protecting C-steel surface over a period of 28 days. The obtained results were further supported by surface examination of steel samples using FE-SEM, EDX and FTIR analyses. Theoretical study involved quantum chemical calculations and molecular dynamics simulation is also performed for the two most abundant components in lemongrass extract (neral and geranial).
\end{abstract}

\section{Introduction}

Corrosion of carbon steel (C-steel) in the presence of produced oilfield water is a common problem across petroleum industries. ${ }^{1-3}$ Produced oilfield water (also called formation water) exists in natural gas and oil reservoirs and it is rich in huge amounts of dissolved salts such as chloride and sulfate besides corrosive dissolved gases like $\mathbf{C O}_{2}$ and $\mathrm{H}_{2} \mathrm{~S}^{4}$

Many synthetic organic corrosion inhibitors are used to protect metals from corrosion but most of them are highly toxic to both human beings and environment and they are often expensive and non-biodegradable. The toxicity may happen either during the synthesis of the organic compound or during its application. ${ }^{5}$

Nowadays, there is a growing need to produce corrosion inhibitors which are not toxic for human beings and are environmentally safe, being green inhibitors. ${ }^{6}$ Green inhibitors include compounds that are non-toxic to humans, have low environmental impact, are biodegradable and maintain their efficiency and cost-effectiveness. ${ }^{7,8}$ The extracts of plant parts such as leaves, peels, seeds, fruits and roots have been reported as effective corrosion inhibitors for metals in different aggressive environments. ${ }^{\mathbf{9}, \mathbf{1 0}}$ Therefore, the use of natural products extracted from plants as corrosion inhibitors has become a key area of research as they are extremely rich sources of naturally synthesized chemical compounds that are biodegradable, renewable, and cost-effective as well as can be extracted by simple methods. ${ }^{\mathbf{1 1 , 1 2}}$ Plant extracts generally contain mixtures of

${ }^{a}$ Egyptian Petroleum Research Institute (EPRI), PO Box 11727, Nasr City, Cairo, Egypt. E-mail: hamadadeiab@yahoo.com; Fax: +20 222747433; Tel: +20 1006137150

${ }^{b}$ Chemistry Department, Faculty of Science, Cairo University, Giza, 12613, Egypt organic compounds including hetero atoms, multiple bonds and aromatic rings. ${ }^{13}$

Although there are several studies on the corrosion inhibition effects of plant extracts in acidic solutions, ${ }^{11-13}$ the data regarding the use of plant leaves extract as the corrosion inhibitor in produced oilfield water is poor.

Lemongrass, cymbopogon citratus, is an aromatic plant used in traditional foods due to its lemon flavor and it is also employed in popular medicine. So, its leaves constitute a source of essential oil for the flavor and fragrance industries. ${ }^{\mathbf{1 4}}$ Lemongrass contains mainly two citrals as major constituents which are a natural combination of two isomeric aldehydes, namely geranial ( $\alpha$-citral) and neral ( $\beta$-citral). ${ }^{15-17}$ Tajidin et al. ${ }^{15}$ have found that lemongrass contains only seven compounds with concentrations greater than $1 \%$ at different maturity stages which are namely, geranial (37.58-44.95\%), neral (29.44$31.13 \%)$, $\beta$-myrcene (3.18-7.68\%), nerol (3.14-3.73\%), 3-undecyne $(1.46-6.08 \%)$, geranyl acetate $(1.06-2.16 \%)$ and juniper camphor $(1.56-2.82 \%)$.

In continuation of our work on development of green compounds as corrosion inhibitors in petroleum filed, ${ }^{18}$ we have studied the inhibiting effect of lemongrass (cymbopogon citratus) extract for carbon steel corrosion in produced oilfield water using weight loss method, electrochemical impedance spectroscopy (EIS) and quantum chemical calculations.

To the best of our knowledge lemongrass (cymbopogon citratus) extract has been used here as a corrosion inhibitor for carbon steel in produced oilfield water for the first time. Furthermore, the novelty of this work is concerning with using quantum chemical calculations for the components in LGE, to know the possible active centre responsible for the adsorption process. 


\section{Materials and methods}

\subsection{Materials}

Carbon steel samples used in the present study have the following chemical composition (wt\%): $0.200 \mathrm{C}, 0.350 \mathrm{Mn}$, $0.024 \mathrm{P}, 0.003 \mathrm{Si}$ and balance Fe. The working electrode and coupons were abraded before each test with a series of emery papers ranging from 400 to 2500 grades, degreased with acetone, washed with distilled water and dried by a filter paper.

The water extract of Lemongrass (LGE) has been purchased from Symrise Co. under the trade mark Extrapone ${ }^{\circledR}$ and was assessed as an inhibitor in this study. LGE is an aqueous glycolic preparation of extract of the plant cymbopogon citratus. It was extracted from the dried leaves by steam distillation. LGE extract has a lemony smell and dark yellow color, with a watery viscosity. HPLC (model: Inertsil ODS) was used to study main chemical components of LGE extract. It is observed that the seven major compounds were identified and quantified with different retention times. The results demonstrated that geranial, neral, $\beta$-myrcene, nerol, 3-undecyne, geranyl acetate and juniper camphor are qualitatively important components in LGE extract. ${ }^{15}$ The chemical structures of these compounds are shown in Fig. 1.

The corrosive medium is the solution of produced oilfield water collected from an oil well at western desert in Egypt. The physical properties and chemical composition of the produced oilfield water sample are shown in Tables 1 and 2, respectively.

\subsection{Methodology}

2.2.1. Weight loss tests. For weight loss experiment, carbon steel coupons of dimensions $1.0 \mathrm{~cm} \times 0.9 \mathrm{~cm} \times 0.3 \mathrm{~cm}$ were accurately weighed with an analytical balance and immersed in $100 \mathrm{~mL}$ produced oilfield water without and with different concentrations of the inhibitor for up to one week (168 h). The loss in weight after a definite immersion time was determined<smiles>CC(C)=CCC/C(C)=C\C=O</smiles><smiles>C=CC(=C)CCC=C(C)C</smiles>

$\beta$-myrcene<smiles>CC(C)=CCCC(C)=CC=O</smiles>

Geranial<smiles>CC(C)=CCC/C(C)=C\CO</smiles>

Nerol
Fig. 1 Major components in cymbopogon citratus plant.
Table 1 Physical properties of the produced oilfield water

\begin{tabular}{|c|c|}
\hline Physical property & Value \\
\hline Total dissolved solids & $111925.5 \mathrm{mg} \mathrm{L}^{-1}$ \\
\hline Conductivity & $14.61 \mathrm{mho} \mathrm{cm}^{-1} @ 20.1{ }^{\circ} \mathrm{C}$ \\
\hline Resistivity & $0.06845 \mathrm{Ohm}$ m@20.1 ${ }^{\circ} \mathrm{C}$ \\
\hline Salinity & $109507.2 \mathrm{mg} \mathrm{L}^{-1}$ \\
\hline $\mathrm{pH}$ & $6.85 @ 25{ }^{\circ} \mathrm{C}$ \\
\hline Density & $1.08418 \mathrm{~g} \mathrm{~mL}^{-1} @ 15.56{ }^{\circ} \mathrm{C}$ \\
\hline Specific gravity & 1.08526 \\
\hline Hardness & $25065.7 \mathrm{mg} \mathrm{L}^{-1}$ \\
\hline
\end{tabular}

by taking out the coupons from the electrolyte, washing thoroughly with distilled water, dried and reweighed. The weight loss tests were performed in triplicate at $20{ }^{\circ} \mathrm{C}$ for each immersion period, and the average value was taken to evaluate the corrosion rate $(\nu)$ in $\mathrm{mg} \mathrm{cm} \mathrm{cm}^{-2} \mathrm{~h}^{-1}$ and inhibition efficiency $E_{\mathrm{w}} \%$ using the following equations: ${ }^{19}$

$$
\begin{gathered}
\nu=\frac{\Delta w}{t \times A} \\
E_{\mathrm{w}} \%=\frac{\nu_{0}-\nu}{\nu_{0}} \times 100
\end{gathered}
$$

where $\nu_{0}$ and $\nu$ are the corrosion rates of carbon steel in blank produced oilfield water and in the presence of inhibitor, respectively, $\Delta w$ is the weight loss of the specimens in $\mathrm{mg}, A$ is the total surface area of specimens in $\mathrm{cm}^{2}$ and $t$ is the immersion time in hours.

2.2.2. Electrochemical tests. A conventional three-electrode glass cell having a capacity of $100 \mathrm{~mL}$ was utilized in all electrochemical experiments. A large platinum sheet with dimensions $20 \times 10 \times 2 \mathrm{~mm}^{3}$ and a saturated calomel electrode (SCE) served as counter and reference electrodes, respectively. The tip of the Luggin capillary included in the cell design was designed to be very close to the surface of the working electrode so as to minimize IR drop. ${ }^{20}$ The working electrode was made from the carbon steel sample with an exposed surface area of $0.285 \mathrm{~cm}^{2}$. All electrochemical experiments were carried out without stirring or deaeration of the test solution using the electrochemical workstation Zahner-electrik IM6e provided with Thales software. Before AC impedance experiments, open circuit potential of the working electrode is measured with time till reaching

\begin{tabular}{|c|c|c|c|}
\hline Constituents & $\begin{array}{l}\text { Concentration } \\
\left(\mathrm{mg} \mathrm{L}^{-1}\right)\end{array}$ & Constituents & $\begin{array}{l}\text { Concentration } \\
\left(\mathrm{mg} \mathrm{L} \mathrm{L}^{-1}\right)\end{array}$ \\
\hline Lithium & 0.01 & Fluoride & 0.000 \\
\hline Sodium & 30543.00 & Chloride & 66368.00 \\
\hline Potassium & 3402.13 & Bromide & 209.45 \\
\hline Magnesium & 1197.24 & Nitrate & Nil \\
\hline Calcium & 8063.85 & Hydroxide & Nil \\
\hline Iron & 38.69 & Carbonate & Nil \\
\hline Copper & 0.15 & Bicarbonate & 244 \\
\hline Strontium & Nil & Sulfate & 1859.00 \\
\hline Barium & Nil & & \\
\hline
\end{tabular}

Table 2 Chemical composition of the produced oilfield water 
a steady state value $\left(E_{\mathrm{ss}}\right)$ after about $30 \mathrm{~min}$. EIS experiments were conducted at $E_{\mathrm{ss}}$ using sinusoidal perturbation signal of $10 \mathrm{mV}$ peak to peak amplitude while the frequency is varied over the range $100 \mathrm{kHz}$ down to $0.01 \mathrm{~Hz}$ with at least four points per decade. The corrosion inhibition efficiency $\left(E_{\mathrm{i}} \%\right)$ of LGE was calculated from the value of the total resistance $\left(R_{\mathrm{t}}\right)$ of the metal surface $\left(R_{\mathrm{t}}=R_{\mathrm{f}}+R_{\mathrm{ct}}\right)$, where $R_{\mathrm{f}}$ and $R_{\mathrm{ct}}$ being the film and charge transfer resistances obtained from EIS measurements, according to the following equation: ${ }^{21}$

$$
E_{\mathrm{i}} \%=\frac{R_{\mathrm{t}}-R_{\mathrm{t}(0)}}{R_{\mathrm{t}}} \times 100
$$

where $R_{\mathrm{t}(0)}$ is the total resistance of the metal surface in blank produced oilfield water and $R_{\mathrm{t}}$ is its value in LGE-containing produced oilfield water.

\subsection{Surface analysis}

Surface morphology was investigated for C-steel coupons immersed 7 days in produced oilfield water solutions free and containing $400 \mathrm{ppm}$ LGE. The scanning electron microscope used was a SEM Model Quanta 250 FEG (Field Emission Gun) equipped with energy dispersive X-ray analyzer (EDX) unit, with an accelerating voltage of $30 \mathrm{kV}$, magnification of $14 \times$ up to 1 million and resolution for the gun of $1 \mathrm{n}$ (FEI Company, Netherlands).

FTIR analysis is performed for the corrosion products to confirm the adsorption of inhibitor molecules on C-steel surface, where FTIR spectra for the crude inhibitor and the corrosion products are compared to each other. FTIR analysis was carried out for the corrosion products scratched from carbon steel coupons immersed in produced oilfield water free and containing 400 ppm LGE for 7 days, using a steel scraper after being carefully washed with distilled water three times by decantation and then dried in air. FTIR analysis is performed using Spectrum One spectrophotometer.

\subsection{Computational chemical data}

Quantum chemical calculations and molecular dynamic simulation was performed for the two most abundant components in LGE, namely neral and geranial. Quantum chemical calculations were performed by VAMP module in Materials Studio 6.0 (MS 6.0) software from Accelrys, Inc. Parametric Method (PM3), a semiempirical method, was utilized so as to optimize the molecular geometry of both neral and geranial molecules and also to obtain their quantum chemical parameters. These parameters include the energy of the highest occupied molecular orbital $\left(E_{\mathrm{HOMO}}\right)$, the energy of the lowest unoccupied molecular orbital $\left(E_{\mathrm{LuMO}}\right)$, the dipole moment $(\mu)$, the electron density as well as the molecular surface area $\left(A_{\text {molec }}\right)$. Fukui indices $\left(f^{+}\right.$and $\left.f^{-}\right)$were calculated using DMol3 module in MS 6.0 software using the DND basis set and the Perdew-Wang (PW) local-correlation-density functional.

Molecular dynamics simulation (MDS) was undergone to model the adsorption of neral and geranial molecules on C-steel surface at the molecular level. Fe surface with (100) cleavage was initially optimized to the minimum energy using Discover module in MS 6.0 software. The optimized molecular structures of neral and geranial were then put near Fe (100) surface and Forcite quench module with COMPASS forcefield was used to attain many different low-energy configurations. The lowest energetic adsorption mode of a single molecule for neral and geranial adsorbed on Fe (100) surface was achieved and its corresponding binding energy ( $\left.E_{\text {bind }}\right)$, expressing their interaction with Fe (100), was calculated using the following equation: ${ }^{22}$

$$
E_{\mathrm{bind}}=E_{\mathrm{tot}}-\left(E_{\mathrm{Fe}}+E_{\mathrm{inh}}\right)
$$

where $E_{\text {tot }}$ represents the total energy of the most stable orientation of inhibitor molecule over Fe surface (100). $E_{\mathrm{Fe}}$ and $E_{\mathrm{inh}}$ represent, respectively the energies of iron surface and inhibitor molecules without interaction.

\section{Results and discussion}

\subsection{Weight loss measurements}

Gravimetric method is used to evaluate the corrosion rate and inhibition efficiency for C-steel in produced oilfield water as a function of LGE concentration at ambient temperature of 293 K. As observed in Table 3, the corrosion rate decreases with increasing LGE concentration up to a certain critical concentration. This behavior is likely attributed to the increase in adsorption of LGE molecules at the metal/solution interface with increasing its concentration. ${ }^{23}$ LGE can react with dissolved iron $\left(\mathrm{Fe}^{2+}\right)$ to form an organo-metal complex (Fe-LGE) which precipitates onto the surface and protecting it from the corrosive medium. ${ }^{24}$ The maximum $E_{\mathrm{w}} \%$ value obtained from weight loss method is $58.19 \%$ at 400 ppm. Further increase in LGE concentration above this value results in a small decrease in the corrosion protection. This may be attributed to some reasons, like for example the possible change occurring on the metal surface during transition of some adsorbed LGE molecules from the planar form to the vertical orientation at higher inhibitor addition $(>400 \mathrm{ppm}) .{ }^{25}$ Through this reorientation step some parts of the steel surface will be exposed to the corrosive species leading to relative increase in the corrosion susceptibility of the metal with a subsequent reduction in the inhibition efficacy of LGE.

\subsection{EIS measurements}

EIS is a useful non-destructive technique used to follow the corrosion behavior of bare and protected metallic materials. ${ }^{26}$

Table 3 Corrosion rate and inhibition efficiency ( $E_{\mathrm{w}} \%$ ) from weight loss for C-steel in produced oilfield water as a function of LGE concentration after168 $\mathrm{h}$ immersion at $293 \mathrm{~K}$

\begin{tabular}{llll}
\hline Inhibitor & {$[\mathrm{LGE}](\mathrm{ppm})$} & $\begin{array}{l}\text { Corrosion rate } \\
\left(\mathrm{mg} \mathrm{cm}^{-2} \mathrm{~h}^{-1}\right)\end{array}$ & $E_{\mathrm{w}} \%$ \\
\hline \multirow{2}{*}{ Blank } & - & 5.30 & - \\
LGE & 100 & 2.65 & 49.92 \\
& 200 & 2.57 & 51.57 \\
& 300 & 2.49 & 52.94 \\
& 400 & 2.22 & 58.19 \\
& 700 & 2.36 & 55.55
\end{tabular}


For an ideal metal/solution behavior on Bode format the absolute impedance $(|Z|)$ tends to become resistive (i.e. independent of the frequency, $f$ with zero phase angle, $\Phi)$ at high (HF) and low (LF) frequency ranges and exhibits a capacitive linear behavior with negative slope at medium frequencies (MF) and a phase maximum of $90^{\circ} .{ }^{27}$ However, the obtained EIS shown in Fig. 2 demonstrates that in any tested solution the Bode diagram of C-steel deviates from the ideal behavior and the impedance spectra display two phase maxima. It is also evident that although the measurement was extended down to a very low frequency of $0.01 \mathrm{~Hz}$, no LF resistive segment (horizontal line and $\Phi \sim 0^{\circ}$ ) can be discerned under any conditions. In consistent with this behavior the impedance spectra on the Nyquist format (Fig. 3) exhibit no ideal capacitive semicircles. Instead each plot represents two merging time constants, the one at $\mathrm{HF}$ region appears as a part of small loop linked to another large incomplete one at LF range and deflects upward giving to a slightly inclined line or an arc, which confirms the feature of Warburg impedance $(W) .{ }^{28}$ In the inhibited produced oilfield water, the length of the arc increases with increasing LGE concentration up to $400 \mathrm{ppm}$. This indicates a continuous increase in the corrosion resistance resulting from the increase in the degree of surface coverage $(\theta)$ by the extract molecules. ${ }^{29}$ Upon increasing LGE addition above $400 \mathrm{ppm}$, both of the arc length and its subtended angle slightly decrease denoting a little reduction in the corrosion resistance. The arcs appeared in the Nyquist plots represent parts of depressed semicircles whose centers are located beneath the real axis.

Analysis of the obtained impedance data was done using the selected equivalent circuit (EC) depicted in Fig. 4 which gave satisfactory fitting to the experimental results with an average error of $0.3 \%$. This electrical model was chosen in the light of our previous work. ${ }^{\mathbf{1 8}}$ It is usually done in electrochemical

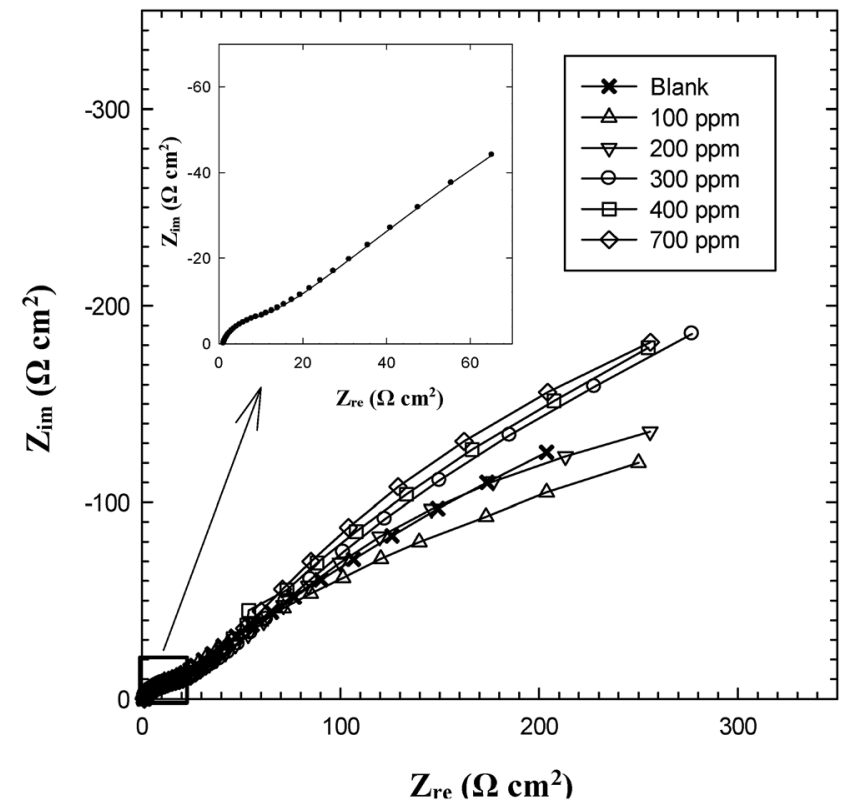

Fig. 3 Nyquist plots for C-steel in formation water as a function of LGE concentration at $293 \mathrm{~K}$. Inset: Nyquist plot for C-steel in blank produced oilfield water.

systems with rough or porous solid surfaces, two constant phase elements $\left(Q_{1}\right.$ and $\left.Q_{2}\right)$ are used instead of the two real capacitance elements to give improved fitting. The model consists of two parallel time constants $\left(Q_{1} R_{1} W\right)$ and $\left(Q_{2} R_{2}\right)$ connected in series with the solution resistance $\left(R_{\mathrm{S}}\right)$. The first time constant $\left(Q_{1} R_{1} W\right)$ describes the behavior of the adsorbed film at LF range, where $Q_{1}$ represents the capacitance $\left(C_{\mathrm{f}}\right)$ of the adsorbed film associated with its dielectric and $R_{1}$ is its resistance $\left(R_{\mathrm{f}}\right)$, while $W$ is the Warburg impedance due to the ionic

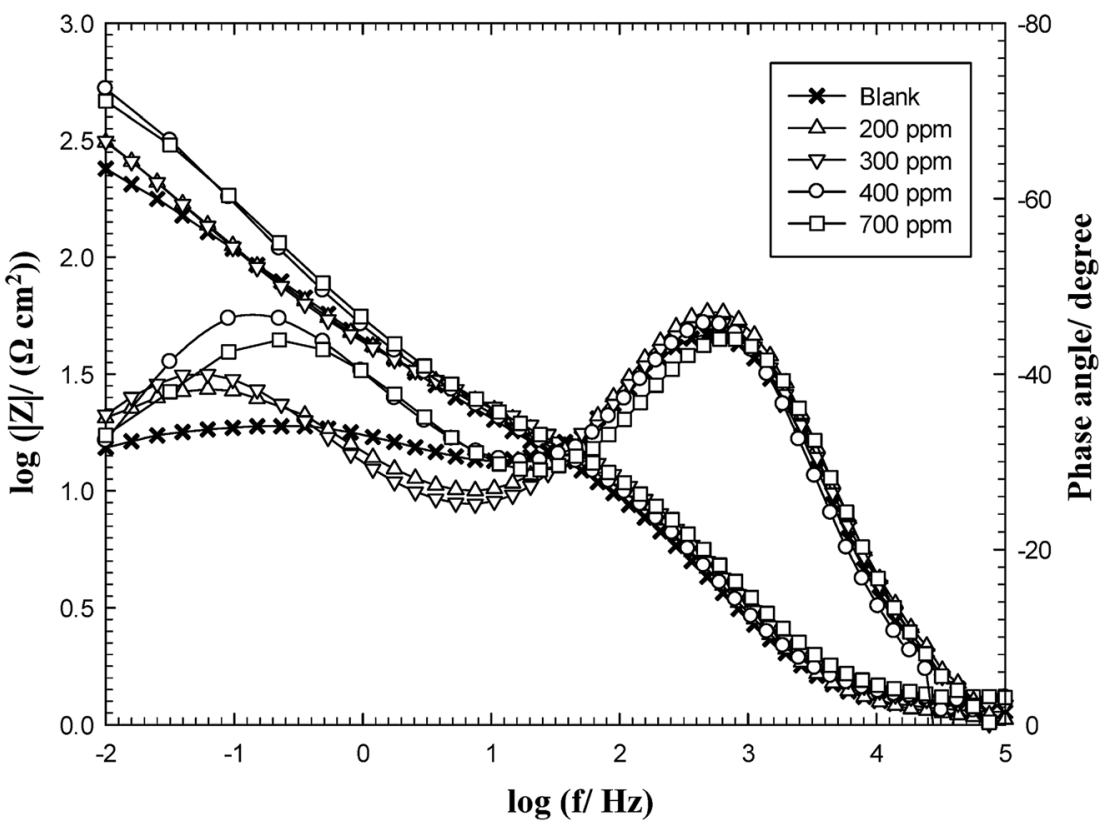

Fig. 2 Bode plots of carbon steel in produced oilfield water as a function of LGE concentration at $293 \mathrm{~K}$. 


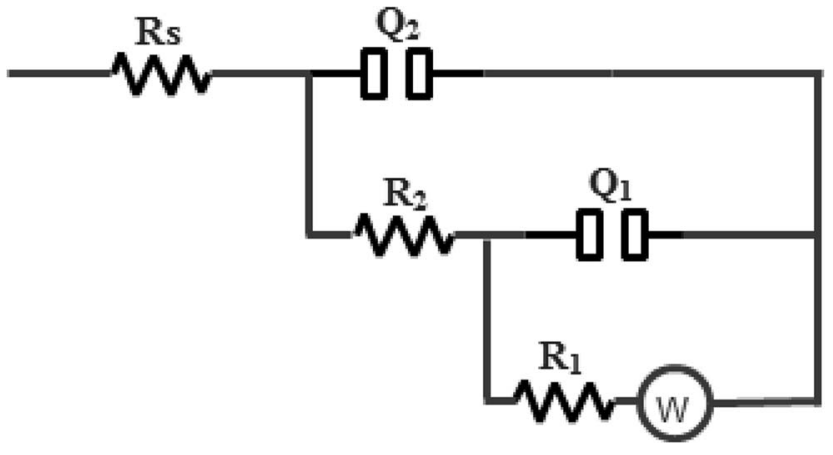

Fig. 4 The equivalent circuit.

diffusion through the film. The second time constant $\left(Q_{2} R_{2}\right)$ corresponds to the double layer capacitance $\left(C_{\mathrm{dl}}\right)$ of the steel/liquid interface through the pores and flaws in the surface film and $Q_{2}$ represents the charge transfer resistance $\left(R_{\mathrm{ct}}\right)$. The impedance of constant phase element $\left(Z_{\mathrm{CPE}}\right)$ is defined as: ${ }^{27}$

$$
Z_{\mathrm{CPE}}=Y^{-1}(j \omega)^{-n}
$$

where $Y$ (in $\Omega^{-1} \mathrm{~s}^{n} \mathrm{~cm}^{-2}$ ) and $n$ are independent of the frequency. The factor $n$ is the CPE power and its deviation from unity is an indication of deviation of $Y$ from the ideal capacitance behavior. $j$ is the imaginary unit $\left(j^{2}=-1\right)$ and $\omega$ is the angular frequency $(\omega=2 \pi f)$. The impedance parameters obtained by fitting are compiled in Table 4 , and from these results the following can be pointed out.

(a) The solution resistance $\left(R_{\mathrm{s}}\right)$ is low and remains nearly constant, ranged between 1.08 and $1.35 \Omega \mathrm{cm}^{2}$ under all conditions due to the good conductivity of tested solutions. ${ }^{30}$

(b) The resistance of the adsorbed film $\left(R_{1}\right)$ is generally with much higher values than those for the charge transfer resistance $\left(R_{2}\right)$, which possesses an almost constant value ranging from $10 \Omega \mathrm{cm}^{2}$ to $19 \Omega \mathrm{cm}^{2}$ in the uninhibited and inhibited produced oilfield water media, respectively.

(c) Upon increasing LGE concentration, a continuous significant increase in $R_{1}$ value is observed. In the blank solution $R_{1}=491.3 \Omega \mathrm{cm}^{2}$ and increases to $1243.7 \Omega \mathrm{cm}^{2}$ at $400 \mathrm{ppm}$ extract addition. After that $R_{\mathrm{f}}$ suffers a small decrease in its value, which marks to a small lowering in the inhibition efficacy of LGE. These results agree well with those obtained from weight loss (Table 3).

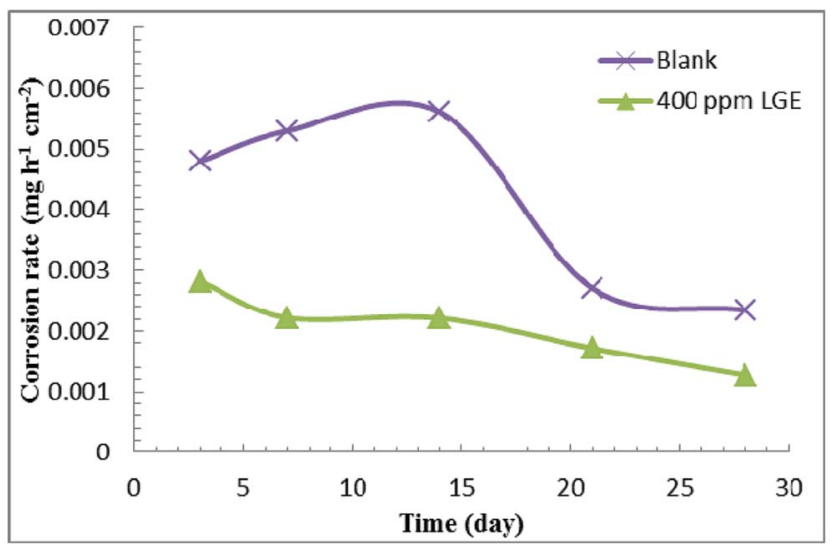

Fig. 5 Effect of immersion time on corrosion rate.

Table 5 Corrosion rates of $\mathrm{C}$-steel samples immersed in blank and 400 ppm LGE-inhibited produced oilfield water as a function of time at room temperature

\begin{tabular}{llr}
\hline & \multicolumn{2}{l}{ Corrosion rate $\times 10^{3}\left(\mathrm{mg} \mathrm{h}^{-1} \mathrm{~cm}^{-2}\right)$} \\
\cline { 2 - 3 } Time (day) & Blank & LGE \\
\hline 3 & 4.80 & 2.82 \\
7 & 5.30 & 2.22 \\
14 & 5.56 & 2.21 \\
21 & 2.76 & 1.72 \\
28 & 2.34 & 1.28
\end{tabular}

(d) Comparing the values of the heterogeneity parameter $(n)$ indicates that $n_{1}<n_{2}$. The average value of $n_{1}$ (relating to the adsorbed film) is $\sim 0.55$ while that of $n_{2}$ (relating to the double layer at steel/solution interface) is $\sim 0.82$, confirming that adsorbed film contains voids and pores. It is also clear that $n_{1}$ value increases with the increase in LGE concentration. This can be attributed to a continuous improvement in the metal surface homogeneity due to adsorption of LGE constituents on its surface. ${ }^{31}$

(e) The growth of the adsorbed film capacitance can be examined in view of high charge accumulation due to the corrosion species adsorbed or the corrosion products formed on C-steel surface ${ }^{48}$ that displayed porous and conducting characteristics as shown by Bonnel et al. ${ }^{32}$ Thus, as revealed by $Q_{1}$ value in the blank produced oilfield water, charge accumulation posing a value of $100.21 \mu \mathrm{F} \mathrm{cm}^{-2}$, which increases with

Table 4 Electrochemical impedance parameters and inhibition efficiency $\left(E_{i} \%\right)$ of C-steel in produced oilfield water as a function of LGE concentration at $293 \mathrm{~K}$

\begin{tabular}{|c|c|c|c|c|c|c|c|c|c|c|}
\hline Inhibitor & {$[\mathrm{LGE}](\mathrm{ppm})$} & $W\left(\Omega \mathrm{cm}^{2} \mathrm{~s}^{-0.5}\right)$ & $R_{1}\left(\Omega \mathrm{cm}^{2}\right)$ & $Q_{1}\left(\mu \mathrm{F} \mathrm{cm}^{-2}\right)$ & $n_{1}$ & $R_{2}\left(\Omega \mathrm{cm}^{2}\right)$ & $Q_{2}\left(\mu \mathrm{F} \mathrm{cm}^{-2}\right)$ & $n_{2}$ & $R_{\mathrm{s}}\left(\Omega \mathrm{cm}^{2}\right)$ & $E_{\mathrm{i}} \%$ \\
\hline Blank & - & 66.23 & 491.34 & 100.21 & 0.47 & 10.10 & 68.11 & 0.82 & 1.13 & - \\
\hline \multirow[t]{4}{*}{ LGE } & 100 & 5.61 & 833.06 & 115.26 & 0.48 & 19.15 & 71.19 & 0.82 & 1.35 & 41.16 \\
\hline & 300 & 0.47 & 1214.67 & 213.19 & 0.54 & 18.50 & 60.70 & 0.79 & 1.21 & 59.34 \\
\hline & 400 & 6.32 & 1243.74 & 207.16 & 0.59 & 13.49 & 67.79 & 0.84 & 1.27 & 60.12 \\
\hline & 700 & 1.61 & 1086.42 & 176.70 & 0.58 & 13.63 & 52.81 & 0.81 & 1.29 & 54.42 \\
\hline
\end{tabular}




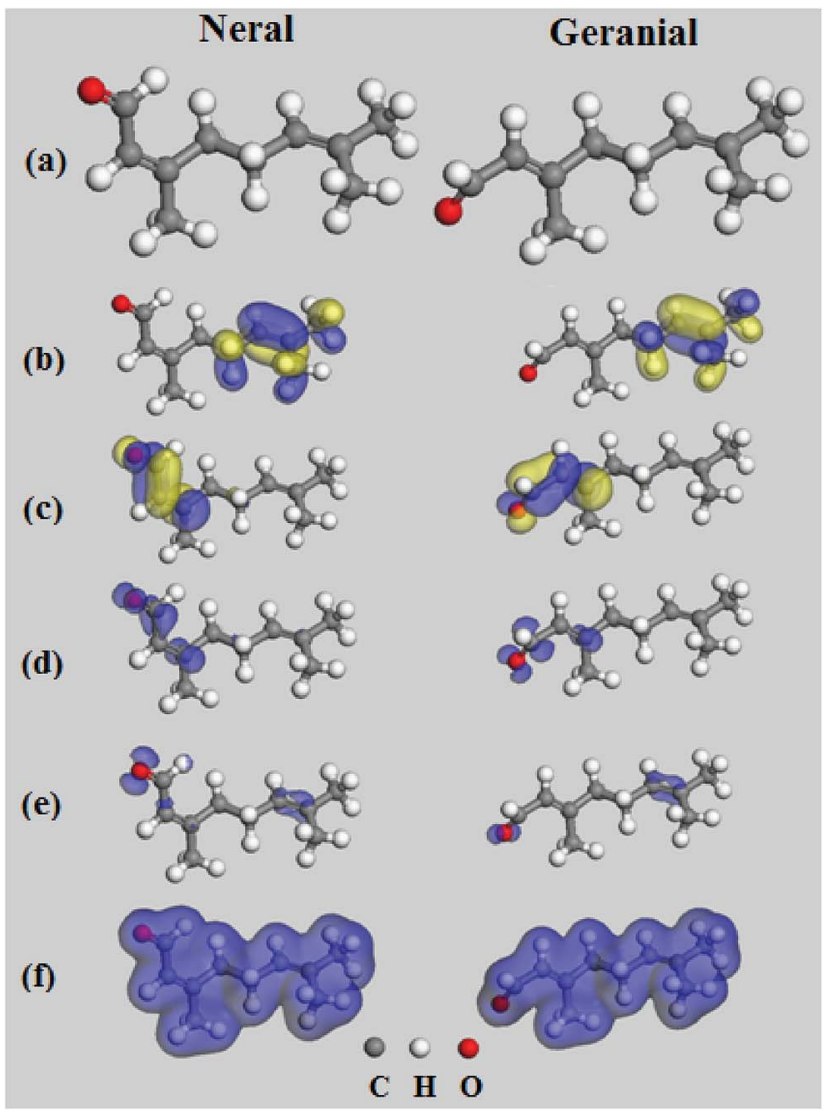

Fig. 6 Electronic properties of Neral and Geranial: (a) optimized structure, (b) HOMO, (c) LUMO, (d) Fukui indices for nucleophilic attack $\left(f^{+}\right)$, (e) Fukui indices for electrophilic attack $\left(f^{-}\right)$and (f) total electron density (atom legend: white $=\mathrm{H}$; gray $=\mathrm{C}$ and red $=\mathrm{O}$ ).

adding LGE. Generally, increasing LGE concentration enhances $E_{\mathrm{i}} \%$ value up to $400 \mathrm{ppm}$ addition. It is thus evident that there is a definite trend in the calculated corrosion inhibition efficiencies obtained from weight loss and EIS measurements.

\subsection{Effect of immersion time}

Fig. 5 and Table 5 show the effect of immersion time on the corrosion rate of C-steel in produced oilfield water in the

Table 6 Calculated quantum chemical parameters for neral and geranial and their binding energies with Fe (100) surface

\begin{tabular}{|c|c|c|}
\hline Parameters & Neral & Geranial \\
\hline$E_{\text {номо }}(\mathrm{eV})$ & -9.59 & -9.53 \\
\hline$E_{\text {LUMO }}(\mathrm{eV})$ & -0.18 & 0.11 \\
\hline$\Delta E(\mathrm{eV})$ & 9.41 & 9.64 \\
\hline$\mu$ (Debye) & 3.65 & 2.69 \\
\hline$A_{\text {molec }}($ sq. §) & 221.32 & 223.96 \\
\hline$I(\mathrm{eV})$ & 9.59 & 9.53 \\
\hline$A(\mathrm{eV})$ & 0.18 & -0.11 \\
\hline$\chi(\mathrm{eV})$ & 4.89 & 4.71 \\
\hline$\eta(\mathrm{eV})$ & 4.70 & 4.82 \\
\hline$\Delta N$ & 0.22 & 0.24 \\
\hline$E_{\text {bind }}\left(\mathrm{kJ} \mathrm{mol}^{-1}\right)$ & -86.09 & -90.18 \\
\hline
\end{tabular}

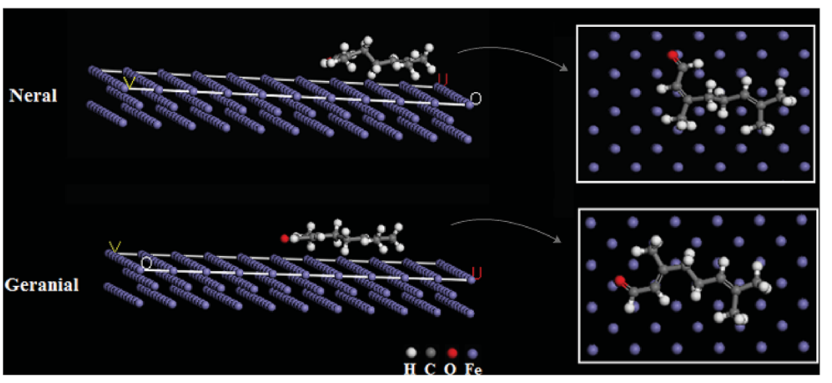

Fig. 7 Molecular dynamics models of the adsorption of single molecules of neral and geranial on Fe (100) surface (atom legend: white $=$ $\mathrm{H}$; gray $=\mathrm{C}$; red $=\mathrm{O}$ and blue $=\mathrm{Fe})$.

absence and presence of $400 \mathrm{ppm}$ LGE, as studied by weight loss method over a period of 28 days. In blank produced oilfield water the results reveal a slow increase in the corrosion rate during the first 13 days of immersion then experiences a sharp decrease till day 21, later on it tends to attain a stabilized value. Meanwhile, in inhibited produced oilfield water the corrosion rate decreases continuously with time. These results indicate that corrosive species in blank water first attack aggressively the C-steel sample, where the corrosion products accumulated on the surface can act as a physical barrier to slow down the corrosion rate. ${ }^{33,34}$ Additionally, the continuous decrease in corrosion rate in inhibited produced oilfield water may be for the reason that adsorption of LGE constituents is preferred to occur on an oxide layer. ${ }^{35}$

\subsection{Computational chemical study}

Fig. 6 displays the optimized geometry of neral and geranial compounds and their HOMO and LUMO distributions, the Fukui indices as well as distribution of their electron densities.

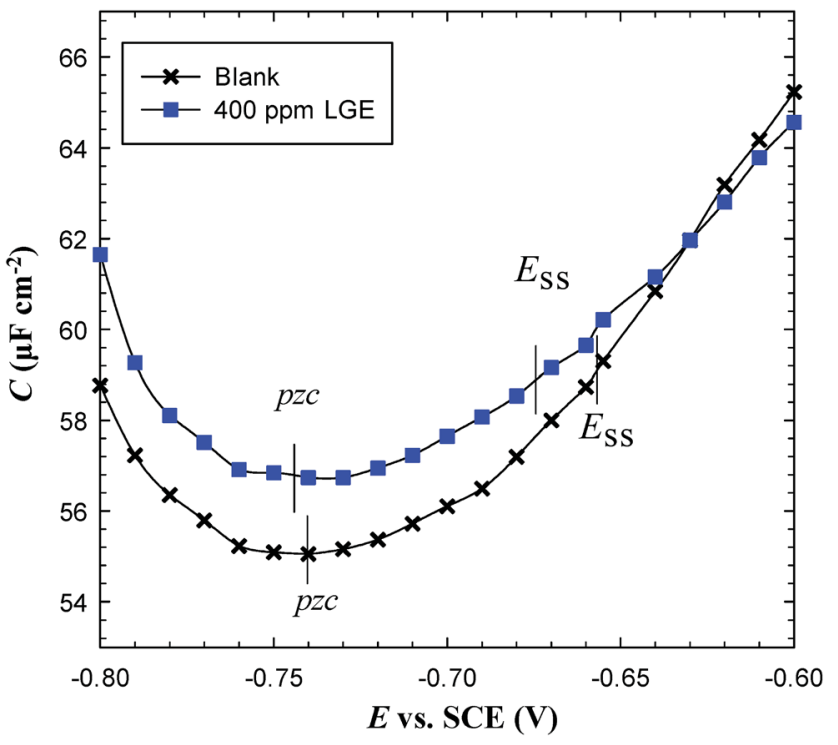

Fig. 8 Variation of capacitance as a function of potential applied on Csteel in produced oilfield water in absence and presence of 400 LGE at $293 \mathrm{~K}$. 
Since the two compounds are stereoisomers, they have the same molecular structure differing only in the orientation of terminal aldehyde group and methyl group across the double bond, i.e. the two groups are in trans-configuration for neral and in cisconfiguration for geranial. Both compounds resemble each other in HOMO and LUMO distributions. HOMO locations lay over the two terminal methyl groups extending over the double bond in contact with them. LUMO regions involve $\mathrm{O}=\mathrm{C}-\mathrm{C}=\mathrm{C}-$ segment rich in $\pi$ electrons and free lone pairs of electrons. The Fukui indices determine the local reactivity of molecules in terms of nucleophilic $\left(f^{+}\right)$and electrophilic attack $\left(f^{-}\right) \cdot{ }^{36}$ It is evident that the $f^{-}$functions of both molecules involve the carbonyl group and the double bond linked to the two terminal methyl groups. Despite the resemblance in the molecular structure between neral and geranial, Table 6 shows that there are some differences in the calculated quantum chemical parameters for neral and geranial. The energy of (HOMO) of geranial is higher $(-9.53 \mathrm{eV})$ than that of neral $(-9.59 \mathrm{eV})$ denoting that geranial has a higher ability for electron donation to Fe surface atoms than neral. ${ }^{36}$
The fraction of electrons transferred from the inhibitor molecule to the iron $(\Delta N)$ was calculated according to eqn (6): ${ }^{37}$

$$
\Delta N=\frac{\chi_{\mathrm{Fe}}-\chi_{\mathrm{inh}}}{2\left(\eta_{\mathrm{Fe}}+\eta_{\mathrm{inh}}\right)}
$$

where $\chi$ is the absolute electronegativity and $\eta$ is the absolute chemical hardness. These two quantities are related to the ionization potential $(I)$ and the electron affinity $(A)$ where: $\chi=\frac{I+A}{2}$ and $\eta=\frac{I-A}{2}, I$ and $A$ being calculated as: $I=$ $-E_{\mathrm{HOMO}}$ and $A=-E_{\mathrm{LUMO}}$.

The theoretical values of $\chi_{\mathrm{Fe}}$ and $\eta_{\mathrm{Fe}}$ are $7 \mathrm{eV} \mathrm{mol}^{-1}$ and $0 \mathrm{eV}$ $\mathrm{mol}^{-1}$, respectively. ${ }^{38}$ The value of number of electrons $(\Delta N)$ transferred from geranial molecule $(\Delta N=0.24)$ is higher than that transferred from neral molecule $(\Delta N=0.22)$ and the former is less electronegative $(\chi=4.71 \mathrm{eV})$ than the latter $(\chi=$ 4.89) which also supports that geranial has a higher ability for electron donation than neral. The calculated molecular surface area $\left(A_{\text {molec }}\right)$ for geranial is higher than that of neral which may provide a higher degree of surface coverage when adsorbed on
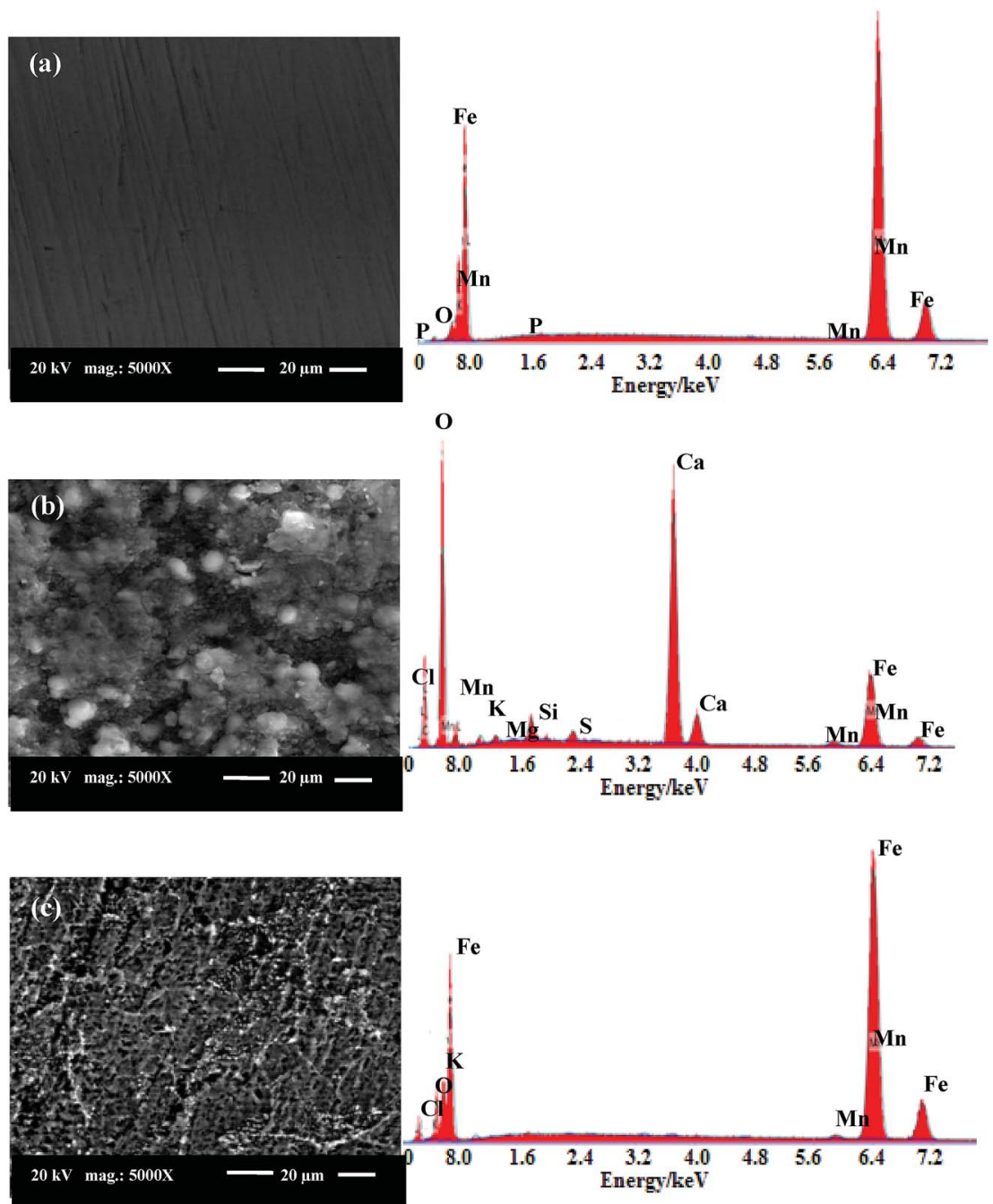

Fig. 9 SEM and EDX images for: (a) abraded CS surface (b) surface of CS immersed in a solution of formation water (c) surface of CS immersed in a solution of produced oilfield water inhibited by 400 ppm lemongrass extract. 

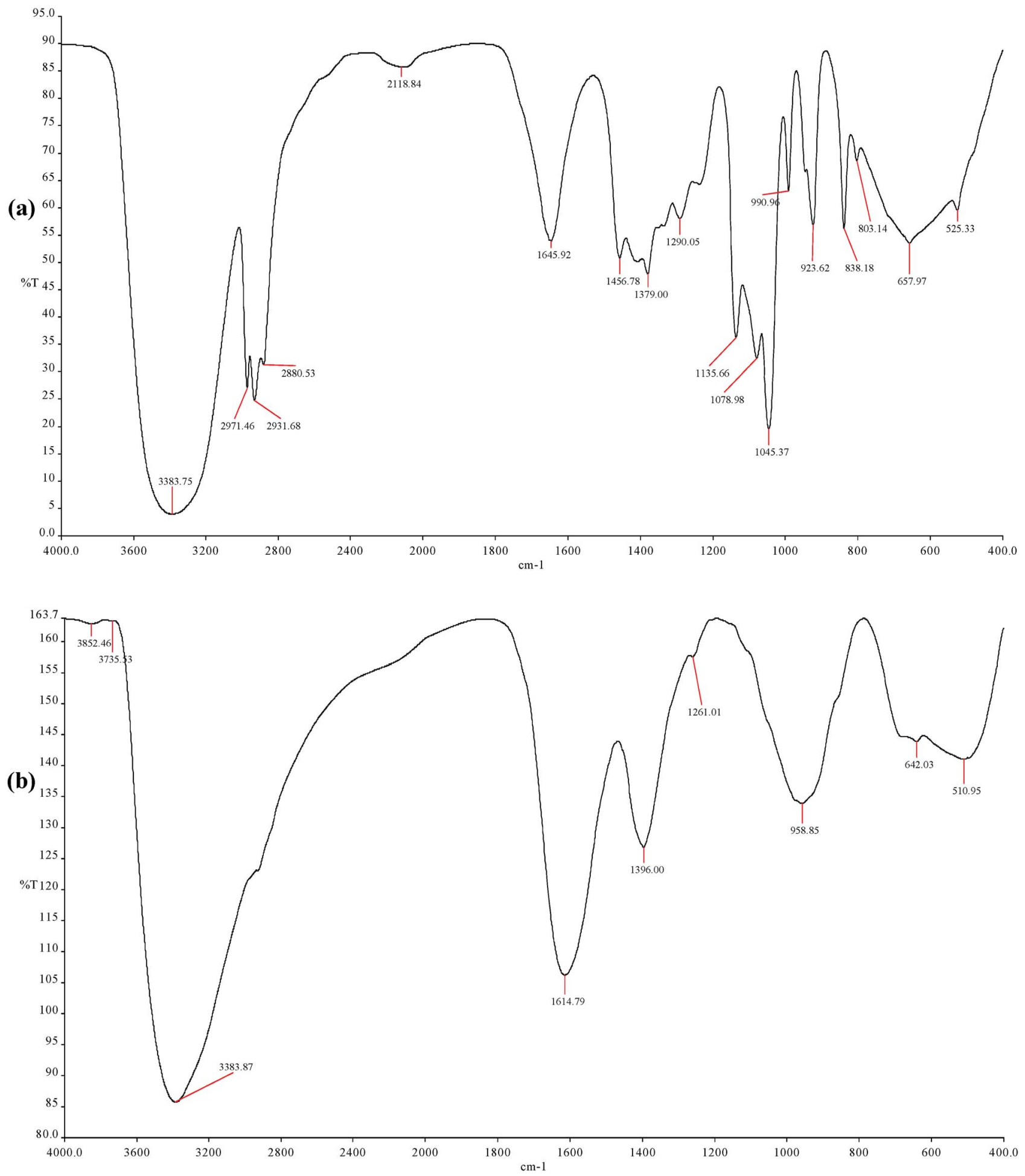

Fig. 10 FT-IR spectra of: (a) Crude LGE. (b) CS surface products.

Fe than the latter. The dipole moment $(\mu)$ is related to the distribution of electrons in the molecule and it is considered a measure of polarity in a bond. ${ }^{38} \mathrm{~A}$ low value of the dipole moment indicates a possibility for accumulation of inhibitor molecules on the metal surface. $\mu_{\text {geranial }}$ is lower than $\mu_{\text {neral }}$ indicating that geranial may inhibit Fe corrosion better than neral. Additionally, there is a linear relationship between binding energy and corrosion inhibition efficiency, where a high negative value of binding energy $\left(E_{\text {bind }}\right)$ indicates a high corrosion inhibition efficiency..$^{39}$ Geranial has higher negative value of $E_{\text {bind }}\left(-90.18 \mathrm{~kJ} \mathrm{~mol}^{-1}\right)$ as compared to that of neral $\left(-86.09 \mathrm{~kJ} \mathrm{~mol}^{-1}\right)$, denoting theoretically that the former has 
a more contribution in the inhibitive effect than neral. Therefore, the trend of calculated binding energies are compatible with the other quantum parameters in the sense that a good corrosion inhibitor has high $E_{\text {HOMO }}$ and high negative value of $E_{\text {bind }}$ in addition to having a low $\chi$ and $\mu$ values. Thus, geranial is slightly more effective than neral in corrosion inhibition of Csteel. Molecular dynamics models (Fig. 7) displays that both neral and geranial adsorb on Fe surface via lateral interaction.

\subsection{Inhibition mechanism}

The potential of zero charge (pzc) assigns the state at which the surface is free from charges, and thus can help to explain the inhibiting nature of the tested material. ${ }^{40}$ As can be seen in Fig. 8 the experimental pzc values of C-steel in blank and inhibited produced oilfield water by $400 \mathrm{ppm}$ LGE are found both to be more negative than their corresponding corrosion potential values. This means that C-steel surface in both solutions is positively charged at the free corrosion conditions. Therefore, inhibitor molecules could be adsorbed on the metal/ solution interface by one or more of the following scenarios. ${ }^{\mathbf{4 1}}$ (i) Donor-acceptor interactions between the $\pi$-electrons in LGE constituents and vacant d-orbitals of iron surface atoms. (ii) Unshared electron pairs of the hetero $\mathrm{O}$ atom and vacant $\mathrm{d}$ orbital of iron surface atoms. (iii) Interaction of filled orbitals of iron surface atom with vacant orbitals of hetero atoms (backdonation). The most effective organic corrosion inhibitors are usually not only those offering electrons to unoccupied dorbitals of the metal, but also accepting free electrons from the metal surface. ${ }^{42}$ Natural products in plant extracts are generally rich in functional groups that allow them to undergo both modes of interaction between C-steel surface and LGE constituents. ${ }^{43}$ LGE has mainly geranial and neral containing aldehydic groups that possess oxygen atoms, in addition to other compounds such as $\beta$-myrcene containing $\pi$-electrons (Fig. 1).

EDX spectra and their corresponding SEM micrographs of the surfaces of C-steel coupons immersed in uninhibited and inhibited produced oilfield water were recorded in order to observe changes occurred during corrosion process in absence and presence of the inhibitor. Fig. 9(a) is the image of polished C-steel surface where slight scratches occurred by emery papers are clearly visible on the surface. The elements constituting carbon steel sample (Fe, Mn, C and P) appears on the EDX spectrum of the abraded sample in addition to oxygen signal related to the air-formed oxide film. ${ }^{44}$ Fig. 9(b) shows that Csteel coupon in blank produced oilfield water is extremely damaged and the sample surface is full of roughness and cavities. Its corresponding EDX spectrum displays signals for $\mathrm{Ca}, \mathrm{Mg}, \mathrm{Cl}, \mathrm{S}$ and $\mathrm{O}$ special for the constituents of produced oilfield water $\left(\right.$ e.g. $\mathrm{Ca}^{2+}, \mathrm{Mg}^{2+}, \mathrm{Cl}^{-}$and $\left.\mathrm{SO}_{4}{ }^{2-}\right)$ as well as iron oxides indicating accumulation of corrosion products (salts and oxides) on the corroded surface. These features may be explained by serious attack of steel coupon immersed in produced oilfield water. In contrast, the coupon immersed in 400 ppm LGE-inhibited solution shows a much improved surface with a fewer amount of corrosion products (Fig. 9(c)).
Table 7 FT-IR absorption bands for crude LGE and its adsorbed film on C-steel surface

\begin{tabular}{lll}
\hline & \multicolumn{2}{l}{ Absorption bands for FT-IR $\left(\mathrm{cm}^{-1}\right)$} \\
\cline { 2 - 3 } Assignment $[18,55,72]$ & Crude LGE & CS surface film \\
\hline OH stretching & 3383.75 & 3383.87 \\
Sym and asym stretching of & $2971.46,2880.53$ & - \\
methyl groups & & \\
C =C stretching & 2118.84 & - \\
C=C-C=O stretching & 1645.92 & 1614.79 \\
Methyl C-H bending & $1456.78,1379.00$ & 1396.00 \\
C-O stretching & $1290.05,1045.37$ & 1261.01 \\
$=$ C-H out-of-bending & 990.96 & 958.85 \\
$=\mathrm{C}-\mathrm{H}$ out-of-plane bending & $923.62-657.97$ & 642.03 \\
$\gamma-\mathrm{Fe}_{2} \mathrm{O}_{3}$ & - & 510.95
\end{tabular}

For this case it can be observed that EDX spectrum corresponding to salts and oxides of the corrosion products is diminished. Surface improvement and reduction in the amount of corrosion products further confirm the anti-corrosion effect and protective performance of LG extract for C-steel in produced oilfield water. ${ }^{45}$

Besides SEM and EDX analyses, FT-IR is a powerful technique for studying the modification in C-steel surface with addition of corrosion inhibitor. FT-IR is used to proof the interaction between organic compounds in the plant extract and C-steel surface. ${ }^{46}$ FT-IR spectra of crude LGE and those for surface film (corrosion products) are shown in Fig. 10. Compared to the spectrum for crude LGE, FT-IR absorption bands of C-steel surface film are shifted from their positions and some of them disappearance (Table 7). These results strongly support the presence of interaction between the natural products in LGE and the metal surface confirming the occurrence of adsorption process. ${ }^{47}$

\section{Conclusions}

The present study evaluates the inhibitive efficacy of lemongrass extract (LGE) for C-steel corrosion in produced oilfield water. The main conclusions are as follows.

(1) Weight loss and EIS measurements showed that LGE has an anti-corrosion effect for carbon steel in produced oilfield water. The inhibition activity increases as a function of concentration up to $400 \mathrm{ppm}$ and decreases slightly above this limit.

(2) EIS data of C-steel in produced oilfield water in absence and presence of LGE is well simulated using an EC model with two parallel time constants and Warburg impedance element indicating the presence of a diffusion limiting step.

(3) The decrease in corrosion rate with both LGE concentration and immersion time suggests that the extract molecules can adsorb on C-steel surface.

(4) Surface analysis (SEM, EDX and FT-IR) further confirms the adsorption of the extract molecules on C-steel surface.

(5) Quantum chemical calculations and molecular dynamics simulations demonstrate that the two most abundant 
components in LGE neral and geranial have comparable tendencies for adsorption on Fe surface, with a slightly higher ability towards electron donation for geranial than for neral.

\section{Conflicts of interest}

There are no conflicts to declare.

\section{References}

1 M. A. Deyab, Inhibition activity of Seaweed extract for mild carbon steel corrosion in saline produced oilfield water, Desalination, 2016, 384, 60-67.

2 M. A. Deyab, B. El Bali, R. Essehli, R. Ouarsal, M. Lachkar and $\mathrm{H}$. Fuess, $\mathrm{NaNi}\left(\mathrm{H}_{2} \mathrm{PO}_{3}\right)_{3} \cdot \mathrm{H}_{2} \mathrm{O}$ as a novel corrosion inhibitor for X70-steel in saline produced water, J. Mol. Liq., 2016, 216, 636-640.

3 M. A. Deyab, K. Eddahaoui, R. Essehli, T. Rhadfi, S. Benmokhtar and G. Mele, Experimental evaluation of new inorganic phosphites as corrosion inhibitors for carbon steel in saline water from oil source wells, Desalination, 2016, 383, 38-45.

4 M. A. Deyab and S. S. A. El-Rehim, Effect of succinic acid on carbon steel corrosion in produced water of crude oil, $J$. Taiwan Inst. Chem. Eng., 2014, 45, 1065-1072.

5 A. Hamdy and N. S. El-Gendy, Thermodynamic, adsorption and electrochemical studies for corrosion inhibition of carbon steel by henna extract in acid medium, Egypt. J. Pet., 2013, 22, 17-25.

6 A. Abdel-Gaber, B. Abd-El-Nabey, I. Sidahmed, A. El-Zayady and M. Saadawy, Inhibitive action of some plant extracts on the corrosion of steel in acidic media, Corros. Sci., 2006, 48, 2765-2779.

7 A. El Bribri, M. Tabyaoui, B. Tabyaoui, H. El Attari and F. Bentiss, The use of Euphorbia falcata extract as ecofriendly corrosion inhibitor of carbon steel in hydrochloric acid solution, Mater. Chem. Phys., 2013, 141, 240-247.

8 M. Znini, L. Majidi, A. Bouyanzer, J. Paolini, J.-M. Desjobert, J. Costa and B. Hammouti, Essential oil of Salvia aucheri mesatlantica as a green inhibitor for the corrosion of steel in 0.5 $\mathrm{M} \mathrm{H}_{2} \mathrm{SO}_{4}$, Arabian J. Chem., 2012, 5, 467-474.

9 J. C. da Rocha, J. A. d. C. P. Gomes and E. D'Elia, Corrosion inhibition of carbon steel in hydrochloric acid solution by fruit peel aqueous extracts, Corros. Sci., 2010, 52, 2341-2348.

10 G. Ji, S. Anjum, S. Sundaram and R. Prakash, Musa paradisica peel extract as green corrosion inhibitor for mild steel in HCl solution, Corros. Sci., 2015, 90, 107-117.

11 S. S. d. A. A. Pereira, M. M. Pêgas, T. L. Fernández, M. Magalhães, T. G. Schöntag, D. C. Lago, L. F. de Senna and E. D'Elia, Inhibitory action of aqueous garlic peel extract on the corrosion of carbon steel in $\mathrm{HCl}$ solution, Corros. Sci., 2012, 65, 360-366.

12 T. Ramde, S. Rossi and C. Zanella, Inhibition of the Cu65/ Zn35 brass corrosion by natural extract of Camellia sinensis, Appl. Surf. Sci., 2014, 307, 209-216.

13 Q. Hu, Y. Qiu, G. Zhang and X. Guo, Capsella bursa-pastoris extract as an eco-friendly inhibitor on the corrosion of
Q235 carbon steels in $1 \mathrm{~mol} \mathrm{~L}{ }^{-1}$ hydrochloric acid, Chin. J. Chem. Eng., 2015, 23, 1408-1415.

14 A. Figueirinha, A. Paranhos, J. J. Pérez-Alonso, C. SantosBuelga and M. T. Batista, Cymbopogon citratus leaves: Characterization of flavonoids by HPLC-PDA-ESI/MS/MS and an approach to their potential as a source of bioactive polyphenols, Food Chem., 2008, 110, 718-728.

15 N. Tajidin, S. Ahmad, A. Rosenani, H. Azimah and M. Munirah, Chemical composition and citral content in lemongrass (Cymbopogon citratus) essential oil at three maturity stages, Afr. J. Biotechnol., 2012, 11, 2685.

16 O. Avoseh, O. Oyedeji, P. Rungqu, B. Nkeh-Chungag and A. Oyedeji, Cymbopogon species; ethnopharmacology, phytochemistry and the pharmacological importance, Molecules, 2015, 20, 7438-7453.

17 E. Korenblum, F. R. de Vasconcelos Goulart, I. de Almeida Rodrigues, F. Abreu, U. Lins, P. B. Alves, A. F. Blank, É. Valoni, G. V. Sebastián and D. S. Alviano, Antimicrobial action and anti-corrosion effect against sulfate reducing bacteria by lemongrass (Cymbopogon citratus) essential oil and its major component, the citral, AMB Express, 2013, 3, 3-44.

18 F. El-Taib Heakal, M. M. Osman, M. A. Deyab and A. E. Elkholy, Electrochemical and Quantum Chemical Studies on the Corrosion Inhibition Potential of Camellia sinensis Leaves Extract for Carbon Steel in Produced Water, Z. Phys. Chem., 2017, DOI: 10.1515/zpch-2017-0949.

19 M. A. Deyab, R. Essehli and B. El Bali, Inhibition of copper corrosion in cooling seawater under flowing conditions by novel pyrophosphate, RSC Adv., 2015, 5, 64326-64334.

20 F. El-Taib Heakal, N. S. Tantawy and O. S. Shehata, Influence of cerium (III) ions on corrosion and hydrogen evolution of carbon steel in acid solutions, Int. J. Hydrogen Energy, 2012, 37, 19219-19230.

21 M. A. Deyab, K. Eddahaoui, R. Essehli, S. Benmokhtar, T. Rhadfi, A. De Riccardis and G. Mele, Influence of newly synthesized titanium phosphates on the corrosion protection properties of alkyd coating, J. Mol. Liq., 2016, 216, 699-703.

22 D. B. Hmamou, A. Zarrouk, R. Salghi, H. Zarrok, E. E. Ebenso, B. Hammouti, M. Kabanda, N. Benchat and O. Benali, Experimental and theoretical studies of the adsorption and corrosion inhibition of 6-phenylpyridazine3 (2H)-thione on Carbon Steel in $2 \mathrm{M} \mathrm{H}_{3} \mathrm{PO}_{4}$ solution, Int. J. Electrochem. Sci., 2014, 9, 120-138.

23 M. A. Deyab, Hydrogen evolution inhibition by L-serine at the negative electrode of a lead-acid battery, RSC Adv., 2015, 5, 41365-41371.

24 G. Gunasekaran and L. Chauhan, Eco friendly inhibitor for corrosion inhibition of mild steel in phosphoric acid medium, Electrochim. Acta, 2004, 49, 4387-4395.

25 A. Moussa, H. Ghaly, M. Abou-Romia and F. El-Taib Heakal, Adsorption and orientation of coumarin molecules on mercury-II: Differential capacitance of mercury in pure and coumarinated aqueous electrolytes: characterization of the adsorption isotherms, Electrochim. Acta, 1975, 20, 489497. 
26 M. A. Deyab, R. Ouarsal, M. Lachkar, B. El Bali and R. Essehli, Phosphites compound: Novel corrosion inhibitor for radioactive waste container (carbon steel) in simulated Callovo-Oxfordian (COx) groundwater, J. Mol. Liq., 2016, 219, 994-999.

27 A. Singh, Y. Lin, E. E. Ebenso, W. Liu, J. Pan and B. Huang, Gingko biloba fruit extract as an eco-friendly corrosion inhibitor for J55 steel in CO 2 saturated $3.5 \% \mathrm{NaCl}$ solution, J. Ind. Eng. Chem., 2015, 24, 219-228.

28 M. A. Deyab, N. H. Mohamed and Y. M. Moustafa, Corros. Sci., 2017, 122, 74-79.

29 H. Bentrah, Y. Rahali and A. Chala, Gum Arabic as an ecofriendly inhibitor for API 5L X42 pipeline steel in $\mathrm{HCl}$ medium, Corros. Sci., 2014, 82, 426-431.

30 Q. Qu, Y. He, L. Wang, H. Xu, L. Li, Y. Chen and Z. Ding, Corrosion behavior of cold rolled steel in artificial seawater in the presence of Bacillus subtilis C2, Corros. Sci., 2015, 91, 321-329.

31 E. Oguzie, C. Enenebeaku, C. Akalezi, S. Okoro, A. Ayuk and E. Ejike, Adsorption and corrosion-inhibiting effect of Dacryodis edulis extract on low-carbon-steel corrosion in acidic media, J. Colloid Interface Sci., 2010, 349, 283-292.

32 A. Bonnel, F. Dabosi, C. Deslouis, M. Duprat, M. Keddam and B. Tribollet, Corrosion study of a carbon steel in neutral chloride solutions by impedance techniques, $J$. Electrochem. Soc., 1983, 130, 753-761.

33 M. A. Deyab, The influence of different variables on the electrochemical behavior of mild steel in circulating cooling water containing aggressive anionic species, $J$. Solid State Electrochem., 2009, 13, 1737-1742.

34 M. A. Deyab, Effect of halides ions on $\mathrm{H}_{2}$ production during aluminum corrosion in formic acid and using some inorganic inhibitors to control hydrogen evolution, $J$. Power Sources, 2013, 242, 86-90.

35 M. A. M. Deyab, Corrosion inhibition and adsorption behavior of sodium lauryl ether sulfate on 180 carbon steel in acetic acid solution and its synergism with ethanol, $J$. Surfactants Deterg., 2015, 18, 405-411.

36 S. S. Abd El-Rehim, M. A. Deyab, H. H. Hassan and A. Abdel Aziz Ibrahim, Influence of nonoxynol-9 on the corrosion inhibition of carbon steel in $1.0 \mathrm{M}$ hydrochloric acid solution, Z. Phys. Chem., 2016, 230, 1641-1653.

37 S. S. Abd El-Rehim, H. H. Hassan, M. A. Deyab and A. Abd El Moneim, Experimental and theoretical investigations of adsorption and inhibitive properties of Tween 80 on corrosion of aluminum alloy (A5754) in alkaline media, $Z$. Phys. Chem., 2016, 230, 67-78.

$38 \mathrm{M}$. A. Deyab and S. S. Abd El-Rehim, Influence of Polyethylene Glycols on the Corrosion Inhibition of Carbon Steel in Butyric Acid Solution: Weight Loss, EIS and Theoretical Studies, Int. J. Electrochem. Sci., 2013, 8, 12613-12627.

39 J. Bartley, N. Huynh, S. Bottle, H. Flitt, T. Notoya and D. Schweinsberg, Computer simulation of the corrosion inhibition of copper in acidic solution by alkyl esters of 5carboxybenzotriazole, Corros. Sci., 2003, 45, 81-96.

40 M. A. Deyab and S. S. Abd El-Rehim, On surfactant-polymer association and its effect on the corrosion behavior of carbon steel in cyclohexane propionic acid, Corros. Sci., 2012, 65, 309-316.

41 D. K. Yadav, M. Quraishi and B. Maiti, Inhibition effect of some benzylidenes on mild steel in $1 \mathrm{M} \mathrm{HCl}$ : an experimental and theoretical correlation, Corros. Sci., 2012, 55, 254-266.

42 F. El-Taib Heakal, A. S. Fouda and M. S. Radwan, Inhibitive effect of some thiadiazole derivatives on C-steel corrosion in neutral sodium chloride solution, Mater. Chem. Phys., 2011, 125, 26-36.

43 M. A. Deyab, Corrosion inhibition of aluminum in biodiesel by ethanol extracts of Rosemary leaves, J. Taiwan Inst. Chem. Eng., 2016, 58, 536-541.

44 M. A. Deyab, Hydrogen generation by tin corrosion in lactic acid solution promoted by sodium perchlorate, J. Power Sources, 2014, 268, 765-770.

45 M. A. Deyab, R. Essehli and B. El Bali, Performance evaluation of phosphate $\mathrm{NaCo}\left(\mathrm{H}_{2} \mathrm{PO}_{3}\right) 3 . \mathrm{H}_{2} \mathrm{O}$ as a corrosion inhibitor for aluminum in engine coolant solutions, $R S C$ Adv., 2015, 5, 48868-48874.

46 M. A. Deyab, Decyl glucoside as a corrosion inhibitor for Magnesium-air battery, J. Power Sources, 2016, 325, 98-103.

47 M. A. Deyab, The inhibition activity of butylated hydroxytoluene towards corrosion of carbon steel in biodiesel blend B20, J. Taiwan Inst. Chem. Eng., 2016, 60, 369-375.

48 M. A. Deyab, Electrochemical investigations on pitting corrosion inhibition of mild steel by provitamin B5 in circulating cooling water, Electrochim. Acta, 2016, 202, 262268. 